\title{
POR QUÉ Y CÓMO HACER ANÁLISIS DE DISCURSO
}

\section{WHY AND HOW TO DO DISCOURSE ANALYSIS}

Dr. Pedro Santander (pedro.santander@ucv.cl) Escuela de Periodismo, Pontificia Universidad Católica de Valparaíso (Valparaíso, Chile).

\section{Abstract}

The following article seeks to be a theoretical and methodological contribution for those who are faced with the task of realizing discourse analysis. In this sense, this text is especially directed to students who intend to perform this task in their thesis. In order to achieve this theoretical and methodological challenge, all along the article, it will be answering two questions: Why doing discourse analysis? and How is discourse analysis performed? As we may observe, the first question is of an explicative nature and the second has a methodological character.

Key words: theory, discourse analysis, sign, text, methodology.

\section{Resumen}

El siguiente artículo busca ser un aporte teórico y metodológico para quienes se enfrentan a la tarea de realizar análisis del discurso. En ese sentido, este texto está especialmente dirigido a estudiantes que piensan llevar a cabo esta tarea en sus tesis de egreso. Para lograr este desafío teórico y metodológico, a lo largo del artículo se responderán dos preguntas: ¿Por qué analizar el discurso? Y ¿cómo hacer análisis del discurso? Como vemos, la primera pregunta es de naturaleza explicativa y la segunda de carácter metodológica.

Palabras clave: teoría, análisis del discurso, signo, texto, metodología.

\section{Introducción}

Analizar los discursos que circulan en nuestra sociedad se ha constituido en un objetivo importante y en una clara tendencia de las Ciencias Sociales y Humanas. Ello tiene mucho que ver con la valoración epistémica del lenguaje y la importancia teórico-metodológica que han adquirido los estudios del discurso, en el marco de lo que se conoce como el Giro Lingüístico (1).

En ese contexto, el Análisis del Discurso ( $A D$ en adelante) se ha consolidado como una útil y recurrida herramienta de análisis, con potencial heurístico importante.

La pregunta de cómo se analizan textos se ha vuelto una cuestión central para las metodologías de las ciencias sociales, tanto por la importancia teórica que ha logrado la noción de discurso, como por la toma de conciencia que se ha adquirido ante el hecho de que la mayoría de los investigadores, tarde o temprano, se 
enfrentan a textos, o a signos de diversa naturaleza (no necesariamente lingüísticos), que requieren ser leídos para su correcta interpretación. Y esa lectura exige análisis.

Esto ocurre no sólo en áreas del saber como la lingüística o la semiótica donde lo anterior pareciera evidente y obvio. Las observaciones etnográficas, la revisión histórica de documentos, la investigación sociológica de la interacción, la sociología del conocimiento, la psicología social, etc., se enfrentan a diálogos, a textos escritos, a entrevistas, etc., es decir, a lenguaje. Además, luego de la necesaria etapa de recolección y confección del corpus que será sometido a análisis, los investigadores producen textos acerca de esos textos en una suerte de doble hermenéutica (ver Sayago 2007).

A lo anterior se agrega la opacidad de los discursos: sabemos que el lenguaje no es transparente, los signos no son inocentes, que la connotación va con la denotación, que el lenguaje muestra, pero también distorsiona y oculta, que a veces lo expresado refleja directamente lo pensado y a veces sólo es un indicio ligero, sutil, cínico.

Esta opacidad plantea, entre otros, toda una línea de discusión semiológica que tiene que ver con la relación entre los signos y sus referentes, discusión de la cual Saussure (1997) prescinde al optar por el principio de inmanencia, pero que Barthes (1971) actualiza, lo mismo que Verón (1984, 1998). A su vez, la evidente opacidad del lenguaje abre una discusión psico-lingüística que permite superar la noción saussuriana clásica que considera al lenguaje como un código (transparente). Ya no basta explicar la comunicación humana como un proceso de codificación y decodificación pues ésta tiene un componente fuertemente inferencial (Grice 1975, Sperber y Wilson 1994), lo que significa que a menudo importa más la inferencia que los signos provocan que el significado literal de ellos, o sea, las palabras significan mucho más de lo que dicen.

Ante esta tricotomía constituida por la importancia analítica de los discursos, la doble hermenéutica y la opacidad de los signos, resulta clara la necesidad de contar con herramientas de análisis que nos ayuden tanto teórica como metodológicamente.

Finalmente, desde una perspectiva más bien política, podemos agregar otro elemento explicativo respecto de la importancia que ha adquirido lo discursivo y sus correspondientes metodologías de análisis en las Ciencias Sociales. Se trata del surgimiento de aquello que Fraser (2003) llama "las luchas a favor del reconocimiento de la diferencia" y que tienen relación con las batallas políticas que se comenzaron a dar a partir de los '80 en torno a temas emergentes como los de sexualidad, género, etnicidad, etc. Nos referimos a dinámicas en cuyo centro encontramos las nociones de identidad y cultura que comienzan a desplazar a otras, como las de redistribución igualitaria, estructura social o la de clase. Evidentemente, en la problemática cultural e identitaria el lenguaje juega un rol central, mucho más prominente que en la problemática de clase social. Y en la búsqueda de explicaciones y soluciones, el discurso es señalado, a menudo, como un lugar donde los prejuicios, estereotipos, representaciones negativas, etc. se re-producen. Finalmente, junto a la cuestión identitaria surge, también en los '80, una corriente que se llama a sí misma "postmarxista" que rescatando ciertos elementos del marxismo, sepultando otros y agregando ideas liberales, pone al lenguaje en el centro de sus argumentaciones teóricas y de su armazón conceptual. Postulan que lo discursivo es una dimensión crucial en el establecimiento de los vínculos y de las relaciones sociales. Exponentes de esta corriente son, por ejemplo, Laclau y Mouffe (2004). 


\section{II. ¿Por qué analizar el discurso?}

Analizar discursos es una tendencia que como indicábamos en la introducción ha logrado importante aceptación en las Ciencias Humanas y Sociales. En lingüística se trata de un movimiento que en su origen dice relación con la necesidad de estudiar el lenguaje en uso, es decir, emisiones realmente emitidas por lo hablantes, superando el principio de inmanencia tan propio de la lingüística saussuriana, interesada en el sistema formal del lenguaje (Ilamado lengua), antes que en su uso real (el habla). A ello se suma la valoración de lo que Verón (1998) y otros autores de la llamada segunda semiología denominan la materialidad de los signos, o sea, los efectos sobre la realidad social que tienen los discursos (constituidos por signos de diferente naturaleza, no sólo lingüísticos).

Por su parte, esta concepción activa del lenguaje también ha influido sobre la psicología social, y en esa área, en los últimos 20 años el AD dejó de considerarse como una herramienta de importancia marginal para pasar a ser una perspectiva empleada frecuentemente y recogida en "un amplio espectro de revistas empíricas y teóricas" (Antaki y otros 2003:2). En sociología, ya mencionábamos a Fraser (2003) y el desplazamiento que ella advierte de categorías sociales modernas como las de clase o estructura por otras que podríamos calificar postmodernas, como las de identidad y cultura, las que tienen mayor cercanía con lo discursivo, lo que, a su vez, influye directamente en la valorización de esta noción (la de discurso) como una categoría clave. En todo caso, esta valoración también es compartida, al menos en parte, por autores como Garretón (2007) -cuyos análisis sociales no pueden ser considerados postmodernos- y quien señala la importancia de analizar los discursos que circulan en y son generados por la sociedad civil, calificándolos como "una pista importante" (Garretón 2007:48) para categorizar sociológicamente las visiones de sociedad civil que están en juego.

Esta convicción de considerar útil leer los discursos para leer la realidad social, se relaciona directamente con el ya mencionado giro discursivo que plantea una perspectiva nueva y alternativa a la de la filosofía de la conciencia respecto de los objetos de estudio y la objetivación de lo conocido. Podríamos decir que con el giro discursivo se pasa de un paradigma que ponía las ideas y la introspección racional en el centro de la observación certera del mundo, a otro que prioriza la observación y el análisis de los discursos. Esto implica un cambio epistémico radical en la mirada científica. Como bien lo aclara Ibáñez (2003), la dicotomía mente/mundo es reemplazada por la dualidad discurso/mundo. En esta visión, el lenguaje no se considera solamente un vehículo para expresar y reflejar nuestras ideas, sino un factor que participa y tiene injerencia en la constitución de la realidad social. Es lo que se conoce como la concepción activa del lenguaje, que le reconoce la capacidad de hacer cosas (Austin 1982) y que, por lo mismo, nos permite entender lo discursivo como un modo de acción. Por consiguiente lo social como objeto de observación no puede ser separado ontológicamente de los discursos que en la sociedad circulan. Estos discursos, además y a diferencia de las ideas, son observables y, por lo mismo, constituyen una base empírica más certera que la introspección racional. Todo lo anterior permite afirmar que el conocimiento del mundo no radica en las ideas, sino en los enunciados que circulan. Como vemos, este paradigma le reconoce al lenguaje una función no sólo referencial (informativa) y epistémica (interpretativa), sino también realizativa (creativa), o, generativa (Echeverría 2003).

En esta misma línea, toda una corriente de estudio conocida como Análisis Crítico del Discurso (ACD) entiende y define el discurso como una práctica social (Fairclough 1992, 2003, van Dijk 2000) y desde esa convicción inicia y justifica sus análisis discursivos como análisis sociales. 
Dicho todo lo anterior, entenderemos por qué, bajo esta perspectiva teórica, se concibe el discurso como una forma de acción. Entonces, en ese sentido, analizar el discurso que circula en la sociedad es analizar una forma de acción social.

\section{Pasos metodológicos iniciales para analizar el discurso}

Antes, una advertencia, sobre todo, después de lo afirmado en torno a la concepción activa y realizativa del discurso: no olvidemos que también la opacidad es una parte inherente del lenguaje y de la producción sígnica en general. Nos encontramos entonces con dos importantes consideraciones que justifican y explican el análisis de los discursos que se producen y circulan en nuestra sociedad: por un lado, son una práctica social (Fairclough 1992, 1995), es decir, nos permiten realizar acciones sociales, por lo mismo, resulta importante analizar los discursos y así tratar de leer la realidad social; por otro, dada la opacidad que acompaña naturalmente a los procesos discursivos, el análisis no sólo es útil, sino que se hace necesario.

Trataremos de graficar y comprender mejor eso de la opacidad efectuando un paralelo pedagógico con un descubrimiento genial de Marx que si bien dice relación con la economía, puede ser aplicado a lo discursivo. Cuando este pensador alemán estudia las prácticas materiales que genera la estructura de la economía capitalista concluye lo siguiente: el carácter real de la práctica económica es ocultado por las apariencias. Esto lleva a Marx a reconocer que la relación entre ideas y realidad está mediada por el nivel de las apariencias, el cual forma parte de la esfera de las formas fenomenales (Marx 2008). De este modo, distingue entre un nivel inmediatamente presente en la superficie de las sociedades capitalistas: el de la circulación (o intercambio) de mercancías, y otro que opera bajo o detrás de la superficie. En parte el verdadero funcionamiento del proceso de producción se manifiesta a través del nivel visible del intercambio, pero, en parte muy importante, también es ocultado por éste mismo nivel (véase Larraín 2007). Es esta distinción entre dos niveles de la realidad el que después lleva a afirmar a Zizek (2003) que es Marx quien inventa la noción de síntoma. Siendo el síntoma lo visible, y aquello que, a su vez, esconde las dimensiones no visibles que le dan forma, que lo sintetizan -y que interesan al analista.

¿Y eso qué tiene que ver con el AD? Es justamente siguiendo esa distinción entre las formas presentes en la superficie discursiva y los procesos opacos en el lado de la producción, entre el síntoma y el núcleo oculto que le da origen y forma, como debemos analizar los discursos, es decir, entenderlos como síntomas, no como espejos que necesariamente reflejan de manera transparente la realidad social, ni los pensamientos o intenciones de las personas. Así, lo que ocurre en el nivel de la circulación de los discursos no es necesariamente un reflejo de lo ocurrido en el nivel de su producción, lo que quedan son huellas, pistas, hebras, síntomas que el analista debe saber describir e interpretar. Porque, claro, si los discursos fueran transparentes, ¿qué sentido tendría hacer análisis? Entonces bien, al entender la opacidad llegamos a la justificación del análisis, y al comprender que el discurso es una forma de acción, encontramos el sentido y el propósito del análisis.

De acuerdo a lo dicho y por lo mismo, el analista del discurso debería asumir que el contenido manifiesto de un texto puede en ciertas circunstancias ser un dato engañoso. En ese sentido, antes que reificarlo, a menudo hay que aceptar la relatividad del dato discursivo (Santander 2007). Distingamos, al respecto, tres situaciones fundamentales que deben formar parte de nuestra claridad teórica previa al análisis: 
- el contenido de un texto, aquello que está en la superficie de la estructura textual, en ocasiones puede resultar confuso, por ejemplo, cuando se emplean iguales estrategias lingüísticas para propósitos antagónicos (Tannen 1996); por ejemplo, el uso del adverbio personal "tú" en ocasiones puede marcar cercanía, pero en otras lejanía entre los interlocutores; o el uso del silencio en la comunicación humana, a veces puede ser una marca de sumisión y otras de protesta.

- En ocasiones lo dicho puede resultar secundario, por ejemplo, cuando el género discursivo prima sobre el contenido del evento, situación ya advertida por Horkheimer y Adorno (1969) y que ocurre, por ejemplo, en el caso de los reality show o de las teleseries donde se repiten siempre los mismos personajes, las mismas situaciones; o incluso en los noticiarios, en los cuales año tras año vemos las mismas noticias acerca de desastres, de delincuencia, del Tercer Mundo, etc.

- O distorsionador, o sea, cuando el lenguaje cumple una función ideológica al describir el mundo (Voloshinov 1992), por ejemplo, ¿por qué nos llaman Tercer Mundo, qué situación describe exactamente la expresión daños colaterales?

Y aquí nos estamos acercando a una dinámica que surgen a menudo en los marcos teóricos de quienes realizan $A D$ y que se relaciona con la práctica social y la opacidad mencionadas: la relación entre discurso e ideología.

\section{Un breve desvío analítico}

Veamos al respecto, y para mayor claridad en torno a la relación entre discurso, ideología y análisis un caso muy propio de la realidad chilena: el llamado conflicto mapuche. Este sintagma nominal forma parte del lenguaje rutinario de la prensa chilena y es empleado permanente y sistemáticamente por los periodistas para referirse y representar esta cuestión. Como vemos, esta opción lingüística reduce a los participantes en el conflicto a un solo actor: el mapuche. De este modo no se menciona, y por lo tanto se invisibiliza a cualquier otro actor que también pudiera formar parte del conflicto, por ejemplo, el Estado chileno, las empresas transnacionales, Carabineros (policía), las empresas forestales, etc. Los mapuches se convierten así en los únicos actores referidos explícitamente. Sin embargo, sabemos objetivamente que en los últimos años jóvenes mapuches como Matías Catrileo (muerto el año 2008) y Alex Lemún (el 2002) fueron asesinados (ver www.matiascatrileo.cl) por personal de Carabineros de Chile, es decir, por agentes del Estado chileno, ¿cabe ahí hablar de conflicto mapuche? ¿O acaso no constituye el sintagma conflicto chileno-mapuche una más certera representación? No estamos ante un conflicto en el que los únicos actores son los mapuches, sin embargo, cuando sistemáticamente se emplea el sintagma mencionado, lo que se está haciendo es ocultar las contradicciones generales de la situación, cosa que no ocurriría si se hablara del conflicto chileno-mapuche, sintagma cuyo uso hace imposible la negación o el ocultamiento discursivo de las contradicciones y que, además, involucra y visibiliza lingüísticamente a la otra parte del conflicto. Como vemos, en casos como éste, todo el sentido del análisis radica en las contradicciones históricas y en los actores sociales que el lenguaje permite invisibilizar; el lenguaje puede ocultar contradicciones y realizar de este modo una acción ideológica muy específica.

Sigamos con el ejemplo y pasemos de la circulación (visible, fenoménica) a la producción (no visible, oculta) de esta expresión mediática. Los periodistas que a diario emplean esta emisión restrictiva e ideológicamente orientada, ¿lo hacen a propósito?, ¿están tomando partido?, ¿diseminan ideología conscientemente?, ¿optan por un sintagma nominal en detrimento del otro a sabiendas? No lo sabemos, eso ya forma parte de las especulaciones y sospechas que podemos tener. Sólo conocemos la acción que se realiza con el lenguaje, la que podemos examinar y analizar empíricamente, en cambio, la intención detrás del autor queda oculta. Sin embargo, lo que permite un $A D$ como el que defendemos, es señalar que lo que el nivel de la circulación 
de estos discursos nos muestra es parcial, que se trata de expresiones ideológicamente condicionadas, sin importar si los periodistas son o no conscientes de ello. De este modo, damos un paso atrás en el proceso y podemos llegar a afirmar que en casos como éste, la producción de los discursos está condicionada ideológicamente de una manera muy determinada. Como vemos, este paso atrás nos lleva al proceso de producción, pero no a la intención de los sujetos.

En ese sentido, es aconsejable distinguir categóricamente entre intención del hablante y la acción de su discurso, porque pensar en la intencionalidad de los sujetos y atribuir a sus dichos intención, implica creer en un sujeto muy racional, siempre atento y conciente de lo que dice o deja de decir, y sabemos que eso no siempre es así.

Estas breves reflexiones analíticas nos muestran que la opacidad del lenguaje, su capacidad de ocultar, no es un impedimento para el análisis, sino su justificación. Asimismo, que nuestro foco está puesto en la acción que se realiza discursivamente y no en la intención que los sujetos tienen al respecto.

\section{Consideraciones metodológicas básicas}

En general, el $A D$ se inscribe en lo que podríamos denominar el saber cualitativo, formando parte de lo que Valles (2000) llama el paradigma interpretativo. Pienso que una muy ilustrativa cita de Canales: "Si la ley del conocimiento cuantitativo podía describirse en la doble medida de lo numerable y lo numeroso, en el caso del conocimiento cualitativo puede encontrarse en la observación de objetos codificados que, por lo mismo, hay que traducir" (2006:19).

Como vemos, esto tiene directamente que ver con la opacidad de los signos que hemos mencionado más arriba, de lo sintomático que pude resultar el discurso y de la asignación de sentido que realiza el analista en el proceso de lectura y traducción. Nos movemos pues en el orden de los significados y sus reglas de significación (Ibáñez 2006) y de la acción que a través de éstos se realiza.

\section{Definición adecuada del problema y lógica de la investigación}

Como en todo proceder investigativo, la correcta y pertinente definición inicial del problema de investigación es clave. Se trata de algún modo del rayado de cancha que el propio investigador fija, por lo tanto, de los márgenes y límites dentro de los cuales se va a mover de cara a su objeto de estudio y al propósito general de la investigación.

En el caso particular del $A D$ es un requisito sine qua non que el problema de investigación -y por lo tanto el objeto de estudio que de éste emanará- sea de naturaleza discursiva y tenga, por lo mismo, una representación sígnica. Esta cuestión puede parecer obvia, pero es crítica: si nuestro problema no tiene representación discursiva, el AD no sirve, ni es pertinente y hay que buscar apoyo en otros instrumentos metodológicos. En ese sentido, no nos olvidemos que nos movemos en el ámbito de lo que Voloshinov llama el mundo de los signos: "al lado de los fenómenos de la naturaleza, de los objetos técnicos y los productos de consumo, existe un mundo especial, el mundo de los signos" (1992:33) (2).

En segundo lugar, señalar que, como en toda investigación, siempre es aconsejable iniciar el problema con una pregunta de investigación que apunte a nuestro objeto de estudio el que, como acabamos de ver, debe ser de naturaleza discursiva. 
De la pregunta de investigación se puede desprender ya sea un objetivo general o una hipótesis. Esta afirmación puede resultar molesta e incluso equivocada para algunos, ya que muchos investigadores consideran incompatible el carácter predominantemente cualitativo del AD con el planteamiento de una hipótesis. En mi opinión y de acuerdo a la experiencia, no hay tal contradicción, ni existe impedimento lógico de trabajar con hipótesis, en tanto éstas estén bien planteadas y su validez pueda ser probada con el AD (por ejemplo, si la variable dependiente es de naturaleza semiótica o lingüística, es decir, discursiva). Tal como lo ejemplifica Sayago (2007), una hipótesis descriptiva como la que sigue es perfectamente válida e incluso requiere para su comprobación del AD.

H1: En el ámbito del aula, la mayoría de los actos de habla que realiza la maestra son directivos.

También podríamos plantear una hipótesis relacional que, en este caso, también demanda AD para su comprobación:

H2: En un contexto de campaña electoral en el cual una candidata mujer lidera las encuestas, los medios contrarios a su candidatura emplearán crecientemente un discurso sexista contra la candidata.

Se trata de hipótesis que van subiendo de nivel de acuerdo a su ámbito de ocurrencia y a su aspiración probatoria; mientras la primera postula algo en un micronivel del aula y se fija en la interacción comunicativa entre una maestra y sus alumnos, la segunda es de nivel intermedio y trata de responder un postulado que tiene que ver con el discurso de los medios y el uso de la estigmatización sexista en ciertos contextos; ambos requieren $\mathrm{AD}(3)$.

Como es lógico, si optamos por trabajar con hipótesis, la comprobación de la misma se convierte en nuestro objetivo general y la lógica de investigación será hipotético-deductiva, pues se parte de la teoría para luego verificar el postulado empíricamente.

$\mathrm{Si}$, en cambio, se opta por una investigación que esté guiada por un objetivo general y, por lo tanto, no atada a una hipótesis, cambia la lógica de la investigación. Cuando nuestra labor está guiada por un objetivo general, ésta es menos lineal (por eso se habla de una investigación guiada y no atada), pues no queremos comprobar un postulado; ahora cumplir el objetivo general es nuestra meta. Es ese logro el que permite dar respuesta a la pregunta de investigación y -bajo la condición de que el objetivo esté bien formulado- lo que genera nuevo conocimiento (Hurtado 2004). En este marco, el proceder será inductivo, es decir, antes que partir de la teoría mediante una formulación inferencial-hipotética, se procede empíricamente guiado por una pregunta y un objetivo general y, en tanto que avanzamos, se va logrando una construcción teórica. En este caso se habla también de un proceder emergente, pues a medida que se avanza en la investigación la teoría va emergiendo, por ejemplo, en forma de categorías de análisis nuevas, o nos vemos en la necesidad de acudir a categorías conceptuales no previstas para interpretar el corpus y volver a éste con mayor seguridad, e incluso, finalizada la labor, se puede concluir el informe proponiendo una hipótesis en base al conocimiento levantado, $y$, de este modo, abrir espacio para futuras investigaciones.

\section{Lógica de investigación y categorías previas o emergentes}

Estas consideraciones generales planteadas hasta ahora en torno a la formulación del problema, deben ser tomadas en cuenta en cualquier investigación, pero tienen consecuencias específicas para el AD y la manera en que llevaremos a cabo el análisis. 
Si optamos por un proceder con base hipotético-deductiva (ejemplos $\mathrm{H} 1$ y $\mathrm{H} 2$ ), nuestro planteamiento teórico general demandará que contemos con categorías previas que apoyen la verificación de la hipótesis. Es decir, en este caso, ya antes de enfrentarnos empíricamente a los discursos en cuestión (textos periodísticos, habla en contextos naturales, signos audiovisuales, etc.) hemos seleccionado, de acuerdo a nuestra hipótesis, a nuestro conocimiento previo y a nuestra teoría, las categorías conceptuales y de análisis que estimamos pertinentes para confrontarlas con nuestro corpus.

Cuando, en cambio, el abordaje del objeto de estudio se realiza en un marco de relativa incertidumbre, de pregunta y objetivo general en vez de hipótesis, lo conveniente es efectuar una investigación de tipo inductivista. En este caso las categorías de análisis no son previas sino emergentes, es decir, en tanto nos enfrentamos a los textos, van emergiendo categorías pertinentes con las cuales analizamos y conceptualizamos nuestro conocimiento obtenido. Por eso es tan importante una correcta formulación de la pregunta de investigación y del objetivo general, pues en nuestro proceder analítico y empírico pueden llamarnos la atención muchos datos interesantes, pero sólo aquellos que apuntan a responder nuestra pregunta y que facilitan el logro del objetivo, son los que se incorporan al análisis y que se consideran como emergentes.

Resumamos. Llegados a este punto contamos con una correcta formulación del problema de investigación, con una pregunta de investigación, con un objeto de estudio cuya representación teórica será de naturaleza discursiva, con una hipótesis o un objetivo general. Si es lo primero, nuestra lógica de investigación será hipotética-deductiva, si no, inductiva. En el primer caso, las categorías de análisis serán previamente formuladas y probadas en el corpus en cuestión, en el segundo caso, éstas emergerán en la confrontación empírica con los textos.

Falta una última consideración antes de llegar al análisis mismo: los signos que analizaremos, ¿serán de naturaleza lingüística o semiótica? Como ya a lo largo de este texto se ha dado a entender, la noción de discurso y, por consiguiente, el AD examinan la generación de significado -la semiosis- en términos generales y consideran que signos de diversa naturaleza (oral, escrita, gestual, audiovisual, espacial, etc.) puede ser leídos -no sólo los lingüísticos. Es decir, el Análisis del Discurso parte de la base que la lengua (escrita y oral) no es el medio exclusivo de representación y comunicación, de lo contrario, el AD no se distinguiría de la Lingüística Textual. En ese sentido, podemos decir que las teorías discursivas se nutren tanto de la primera semiótica (también llamada semiología) que teoriza acerca del signo lingüístico sobre la base de las propuestas estructuralistas de Ferdinand Saussure (1997) y de la segunda semiótica (o semiótica a secas) que amplía su mirada tanto a signos de otra naturaleza como a la relación de esos signos con los contextos sociales, extra lingüísticos.

Si optamos por signos de naturaleza lingüística, realizaremos un AD de orientación lingüística (ADL en adelante); si optamos por otro tipo de material, realizaremos Análisis del Discurso de orientación semiótica (ADS en adelante); respecto de este último caso, autores como Kress y van Leeuwen (1998), prefieren hablar de semiótica discursiva.

En el caso de objetos de estudio como los medios de comunicación pueden ocurrir ambas situaciones: nos puede interesar el análisis de textos en el sentido tradicional, por ejemplo, editoriales, columnas de opinión, titulares, crónicas informativas, etc., o productos semióticos como la imagen fotográfica, animación, teleseries (ver, por ejemplo, Williamson 2002 o Aimone 2007). 


\section{IV. ¿Qué hacer frente a los textos y cómo comienzo a analizar?}

Hemos llegado a la parte empírica del análisis: nos enfrentamos a los textos. Esto no significa que ahora se renuncie a la teoría, de ningún modo. La teoría es un lente con el cual miramos la realidad, por lo mismo, sin ese lente, los textos nos parecerán desenfocados, un mar amorfo de letras, y nos perderemos o ahogaremos en él. La teoría acompaña todo análisis pues incide en nuestro modo de enfrentar el objeto de estudio, de problematizarlo, en las categorías conceptuales y, evidentemente, en cómo mirar los textos.

A menudo esta es la parte más difícil para quienes se inician en el análisis. Puede ocurrir que se tenga claridad acerca del problema de investigación, de la teoría que nos sustenta, de las decisiones muéstrales, etc., y que incluso se realice una correcta recolección del material a analizar y ahí, frente al corpus (diarios, entrevistas transcritas, archivos, documentos multimodales, etc.), surgen las dudas, ¿qué hago ahora que estoy ante el material que debo analizar?, ¿cómo lo analizo?

Dos consideraciones fundamentales que se deben tomar en cuenta cuando se comienza a analizar textos:

(a) No existe la técnica para hacer el análisis. Esta afirmación puede provocar cierta confusión o desazón, pero es así. Lo que existe son muchas propuestas de análisis de diversos autores frente a diferentes problemáticas y motivaciones. Por experiencia he visto que los estudiantes suelen tener la esperanza de encontrar en algún libro las indicaciones exactas que le digan cómo analizar su corpus. Sin embargo, ocurre que, en primer lugar, en los discursos -sean de naturaleza lingüística o semiótica- mucho puede variar: lo que en un texto puede ser muy significativo, en otro puede ser irrelevante. En segundo lugar, el análisis es muy dependiente de nuestro objetivo general o de nuestra hipótesis. Al estar orientado a probar la hipótesis o a cumplir el objetivo general, el tipo de análisis también puede sufrir fuertes variaciones de caso en caso.

Este problema de encontrar la técnica de análisis es un constante dolor de cabeza para todas aquellas disciplinas e investigadores que trabajan y se enfrentan a discursos. La historia del psicoanálisis, por ejemplo, muestra fascinantes discusiones y reflexiones al respecto. Para Freud el lenguaje es un modo de acceder al inconciente y una de las herramientas que permite volver conciente lo inconciente. Sobre esa base lingüística se realiza un análisis interpretativo, y por lo tanto, se justifica el lenguaje como material de análisis: los juegos de palabras, las asociaciones libres y los chistes son material lingüístico con el que se trabaja y que forman parte del método de interpretación freudiano. Método practicado por quienes ya entonces muestran la lucidez suficiente para estar alertas ante la capacidad distorsionadora de lo real que las palabras tienen. Sin embargo Reich (1996), destacado discípulo de Freud, comienza su divorcio con el maestro justamente cuestionándose y cuestionándole la falta de una sólida técnica interpretativa en la terapia que oriente el encuentro paciente-terapeuta, dinámica en cuya base está justamente el lenguaje. Este divorcio entre ambas miradas llega a tal nivel que Reich finalmente emprende un camino propio, distinto, en el cual el lenguaje verbal del paciente juega un rol de menor importancia en la terapia, siendo desplazado por la primacía del lenguaje corporal, de este modo, es ahora el cuerpo el que se convierte en el material sígnico, en el texto que se vuelve legible y que se interpreta como materia significante del inconciente: "las palabras mienten, las expresiones nunca" (Reich 1996:138).

(b) ¿Qué busco en este texto? A mi modo de ver, esta es la pregunta orientadora fundamental para cualquier analista cuando está ante sus textos y que nos ayuda ante el problema qué significa la ausencia de una sola técnica de análisis estándar. Como se señaló en el punto anterior, mucho puede variar en los discursos y el análisis está en gran medida orientado por la hipótesis o el objetivo general que guían la 
investigación. En los corpus podemos encontrar mucha información, sin embargo, para no perdernos, para discriminar entre aquello que interesa y aquello que no interesa (aunque llame la atención), para dirigir la mirada adecuadamente, siempre es aconsejable preguntarse una y otra vez, sobre todo cuando surgen dudas, ¿qué busco en el texto? y para la correcta respuesta se debe recurrir a la problematización inicial y a la pregunta de investigación que motiva mi interés.

Dicho lo anterior, y tal como se señaló en el punto a), existen una serie de propuestas e incluso modelos de análisis que es bueno y útil conocer, siempre y cuando no se olvide que en el $A D$ todo es dinámico, que lo que sirve en una circunstancia, no necesariamente sirve en otra. Sin embargo, puestos como analistas ante diferentes circunstancias, resulta de gran utilidad conocer propuestas analíticas, alguna de las cuales pasamos a mencionar.

La llamada Lingüística Crítica (Fowler et. al. 1983, Hodge y Kress 1979, Fowler 1996), por ejemplo, propone un modelo de análisis Ilamado transactivo-transformacional que intenta relacionar la organización social de la comunidad con la gramática (en sentido amplio) que ésta emplea y ver cómo las pautas socialmente determinadas del lenguaje influyen en el comportamiento no lingüístico. Su unidad de análisis es la oración, su concepción del lenguaje es funcionalista y su mirada social responde al paradigma crítico. De hecho, esta corriente británica analiza tempranamente el discurso medial y lo vincula con lo ideológico.

A su vez, la Gramática Sistémico Funcional (Halliday 1994, Halliday y Hasan 1990), es una propuesta menos política que la anterior, aunque muy usada, por ejemplo, por quienes adscriben al Análisis Crítico del Discurso. También aquí la unidad de análisis es la oración, no obstante, sobre esa base se elabora una interesante y compleja propuesta llamada por algunos “contextualismo británico" que propone vínculos entre texto y contexto. Para eso se distinguen tres dimensiones de todo contexto situacional (campo, modo y tenor) las que se ponen en relación con tres metafunciones del lenguaje (función ideativa, interpersonal e informativa); cada una de estas funciones se expresan gramaticalmente y, por lo mismo, pueden ser descritas mediante recursos lingüísticos como la modalización, agencialidad, tópico y comento, etc.

Fairclough (1992), sobre la base de la Gramática Sistémico Funcional (GSF) agrega una dimensión adicional a las metafunciones del lenguaje -la función ideacional (afirmando que el discurso contribuye a la construcción de sistemas de creencias) - y propone un modelo tridimensional que considera tres niveles de análisis: el análisis textual, el de la práctica discursiva y el de la práctica social; siendo el primero de carácter descriptivo, el segundo interpretativo y el tercero explicativo. Para ello propone siete categorías de análisis, entre las cuales destaca la intertextualidad que, como el mismo Fairclough señala, es la propiedad de los textos de estar constituidos con fragmentos de otros textos.

Los ya mencionados Hodge y Kress (1979) amplían su unidad de análisis y optan por una naturaleza del signo distinta para incursionar en la semiótica discursiva, de la oración pasan a unidades más amplias, para lo cual extrapolan las tres metafunciones del lenguaje que propone la GSF a los textos icónicos.

Sayago (2007), a su vez, propone un AD de cuatro niveles: textual, discursivo, acción social y estructura social. Según el nivel, éstas se nutren de teorías lingüísticas, teorías de medio rango y de teoría social.

Y así se podría seguir con más propuestas, pero reiteramos, no existe el modelo de análisis para todos los textos, éste a veces surge del análisis mismo, otras puede que exista de antemano y se ajuste a mis 
requerimientos y también puede ocurrir que sirva sólo parcialmente y ante las limitaciones el tipo de análisis se construya a medida que se avanza empíricamente.

\section{Coherencia entre categorías teóricas y analíticas}

Si bien no existe un modelo único de análisis, sí se puede afirmar que toda investigación que contemple el análisis discursivo y que quiera enfrentarse exitosamente a la interpretación sígnica, debe mostrar siempre una coherencia rigurosa entre categorías conceptuales, categorías discursivas, categorías lingüísticas/semióticas y recursos gramaticales de base. Bourdieu (2000) hablaba de la "vigilancia epistémica" que debe tener todo análisis social; en nuestra propuesta podríamos hablar de una "vigilancia analítica" que exige que los conceptos teóricos y los analíticos de la investigación estén relacionados con el objeto de estudio y que se apoyen mutuamente para la ejecución del análisis (4). El siguiente cuadro puede ayudar a comprender lo señalado:

\section{Gráfico 1}

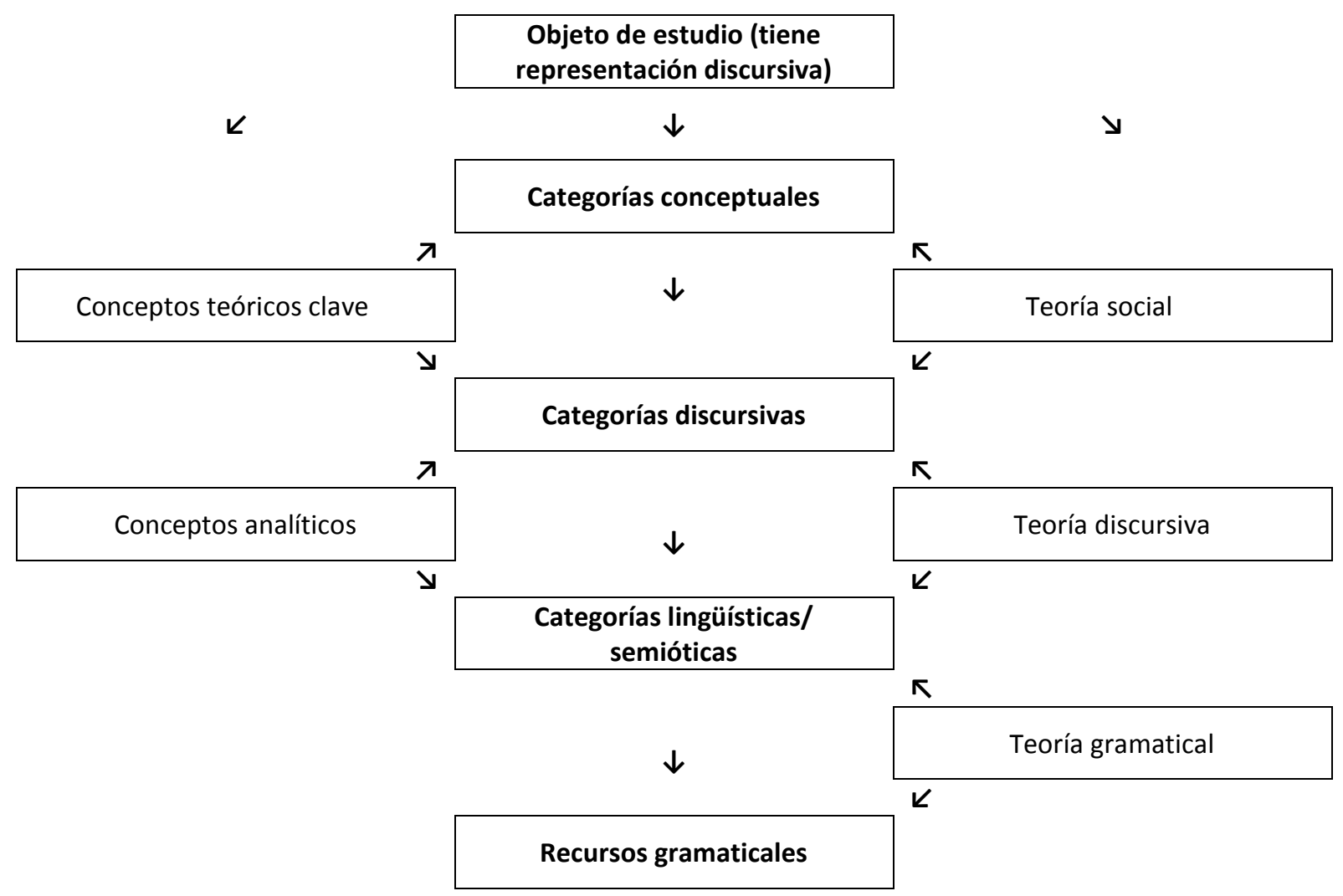

Toda investigación trabaja con un número limitado de conceptos teóricos clave. Estos están en directa relación con nuestro problema de investigación, se adecuan al mismo y forman parte de nuestro marco teórico, son, de hecho, el sostén teórico de nuestra investigación. Cuando decimos que se "adecuan" al problema de investigación queremos decir que nuestra opción por los conceptos claves es totalmente racional y que en el $A D$ los usamos como categorías conceptuales ya que identificamos en ellos una 
dimensión operativa, que es la que nos sirve para iluminar teóricamente el objeto de estudio. Podemos suponer que buscamos algún rasgo de su expresión en los textos, es decir, no se pueden concebir como conceptos aislados del análisis, sino justamente como categorías que se expresan en el corpus.

Es altamente probable (a menudo deseable) que ya en la formulación del problema de investigación (lo que incluye la pregunta de investigación, objetivo o hipótesis) aparezcan y se expliciten dichos conceptos. En el ámbito del $\mathrm{AD}$, por ejemplo, nociones como las de poder, estructura social, ideología, hegemonía, etc., suelen ser empleadas con frecuencia. Lo que motiva muchos análisis es precisamente la curiosidad por explicar el modo en que la ideología, la estructura social, la hegemonía u otras nociones como esas se manifiestan en los discursos, por entender qué huellas dejan elementos del afuera en la producción sígnica y cómo todo ello se interrelaciona.

Estas categorías sociales nos remiten a la teoría social. Por ejemplo, la noción de hegemonía nos lleva a Gramsci, la de poder nos puede llevar a concepciones difusas como la de Foucault o, por el contrario, más centrales como la visión leninista; en tanto, el concepto de ideología lo podemos entender epistémica o funcionalmente, o tener una valoración negativa de la ideología, epistémica o sólo descriptiva, etc.

Como nuestro recorrido nos lleva a signos, seguimos ese desafío y trabajaremos con conceptos analíticos que son de naturaleza discursiva, por eso hablamos ahora de categorías discursivas. En este nivel nos sirve la teoría ligada a lo discursivo. Como ya dije, el concepto de ideología es usado frecuentemente por los practicantes del AD y su expresión buscada y descrita en textos. Pero para que ese concepto pueda ser una categoría operativa, debemos previamente tener un conocimiento cabal del mismo y saber qué tiene qué ver con lo discursivo. Para Voloshinov (1992) todo producto ideológico posee una significación, de modo tal que llega a afirmar que "donde no hay signo, no hay ideología" (Voloshinov 1992:32) y que "la palabra es el fenómeno ideológico por excelencia" (Voloshinov 1992:37). Por su parte, Bourdieu (2003) considera el lenguaje un instrumento de poder y de acción, antes que de comunicación, y prefiere no usar la noción de ideología (o de manera muy cauta) y la reemplaza por la de poder simbólico o dominación simbólica. Otros, como Foucault (1983), derechamente reemplazan la noción de ideología por la de discurso.

Como vemos, estamos en un nivel donde se cruzan teoría social y teoría discursiva, y esta última nos acomoda aquí para dar con las categorías discursivas pertinentes a nuestros propósitos analíticos. Para encontrar las adecuadas miramos preferentemente a autores que han teorizado sobre el discurso, y que al hacerlo, han aportado también a la teoría social, como Bajtin, Barthes, Foucault, Eco, Pierce, Ricoeur, Rorty, Voloshinov, etc. Las categorías que el armazón teórico de esos autores nos proporcionan sirven para enfrentarnos a los textos y buscar su manifestación en los mismos, por ejemplo, nociones como las de polifonía, interdiscurso, formación discursiva, orden del discurso, géneros discursivos, etc.

Estas categorías discursivas deben estar muy relacionadas con lo que llamamos la necesaria representación discursiva de nuestro objeto de estudio; podríamos decir que, por lo mismo, las categorías discursivas están atadas al objeto de estudio.

En mi opinión, estos dos niveles son suficientes para analizar discursos. Hay autores como Foucault, Gadamer, Ricoeur o Rorty que no hacen análisis en el sentido estricto, es decir, no necesariamente bajan a los textos para buscar en ellos el correlato empírico de lo que se postula teóricamente, no obstante, es innegable que sus aportes teóricos son inmensos e indispensables para el $A D$ y para cualquier labor hermenéutica. 
Pero estando ante la necesidad de hacer análisis, eso nos lleva obligatoriamente a un nivel categorial lingüístico o semiótico (según sea la naturaleza del signo que enfrentemos). Lo importante aquí es señalar que las categorías lingüísticas o semióticas son propiedades de las categorías discursivas, una especie de subconjunto que emana del nivel anterior. Cada uno de estos niveles está más cerca del texto mismo y su existencia teórica se aleja cada vez más del mundo extra discursivo y responde más al mundo de los signos (Voloshinov 1992). Por lo mismo, este nivel en el que nos encontramos ahora sólo se actualiza en la textualidad de los signos. Aquí los contornos textuales se vuelven más densos y ya operamos sobre textos, sean de naturaleza lingüística o semiótica. Pierce, por ejemplo, propone tres categorías semióticas muy útiles para analizar textualidades conformadas por signos no lingüísticos: índice, ícono y síntoma. Respecto del análisis de signos de naturaleza lingüística, hemos ya mencionado la Lingüística Crítica o la Gramática Sistémico Funcional. Otras categorías que suelen emplearse son las de tonalización, jerarquización de la información, discurso referido, tematización, modalización, etc.

Respecto del último nivel de los recursos gramaticales al que ahora pasamos, digamos dos cosas. En primer lugar que los recursos gramaticales son propiedad del nivel anterior $y$, en segundo, que suelen ser lingüísticos antes que semióticos. Esto se explica porque la ciencia del lenguaje ha descrito la gramática, es decir, su sistema de signos en forma exhaustiva y formalmente, a diferencia de la semiótica que aún se encuentra en esa empresa. Nos referimos aquí a la caja de herramientas de la que hablaba Saussure, que son recursos gramaticales que nos proporciona la lengua y que están en directa relación con las categorías lingüísticas. Por ejemplo y respecto de las categorías mencionadas en el párrafo anterior: los modos verbales (indicativo, imperativo, subjuntivo) o el uso de formas impersonales del verbo permiten tonalizar; la cohesión secuencial y la estructuras binarias de tema (información de soporte o punto de partida semántico de la oración) y rema (información de aporte o punto de llegada semántico de la oración) de las oraciones facilitan la jerarquización de información; las citas directas e indirectas son expresiones del discurso referido; los verbos auxiliares y los adverbios permiten a los hablantes modalizar, etc.

\section{Ejemplos}

Después de las definiciones, tratemos de mostrar cómo aplicar esa coherencia analítica en ejemplos concretos.

\section{Ejemplo 1}

En mi tesis doctoral me interesó el problema de cómo acceden a los noticiarios de la televisión las fuentes periodísticas y las diferentes voces que hablan en las noticias, y el modo en que éstas son representadas por los medios. En tal caso, acceso y representación fueron dos categorías conceptuales con las que trabajé, a las que se sumó la de visibilidad. Respecto de representación, podemos decir que hay toda una la teoría de la representación que se nutre tanto de la psicología social (las representaciones sociales) como de la semiótica (cómo los signos sirven para representar). La noción de visibilidad ha sido trabajada en el ámbito de los estudios de opinión pública, de la teoría de la esfera pública (Thompson 1998) y a menudo vinculada a los medios. En cuanto al concepto de acceso, fue más difícil encontrar teoría específica, por lo tanto, se recurrió a variadas y diversas fuentes y se armó una propia visión al respecto. Evidentemente, las categorías de fuentes y voces son de naturaleza discursiva, lo que cumple con el llamado requisito discursivo ya varias veces señalado en relación con el objeto de estudio. En cuanto a las categorías discursivas, y siguiendo la vigilancia analítica, trabajé con las de orden del discurso (de los medios), poder sobre/dentro del discurso (de los medios) -pues aquí interesaba saber el grado de poder de las voces que acceden al discurso medial-y de 
polifonía -ya que se trataba de ver el rango, la multiplicidad y variedad de esas voces. La primera noción pertenece a Foucault (1983), la segunda a Fairclough $(1989,1992)$ y la tercera a Voloshinov (1992) -quien habla específicamente del discurso ajeno. Las categorías lingüísticas que usé para ver eso en los textos fueron las de discurso referido (sirve para representación y polifonía) y jerarquización de la información (sirve para poder dentro y sobre el discurso) y acceso (basándome en la propuesta de Pardo 1986 y 1996).

Y en cuanto a los recursos gramaticales, me fijé en las citas (directas, indirectas, pseudodirectas, semánticas, etc.), en las negaciones (esta fue una categoría emergente, que no estaba contemplada previamente, pero que el análisis demandó, pues el uso de negaciones se mostró como una forma de acceso de voces extratextuales a las noticias) y modos verbales, entre otros.

\section{Gráfico 2: Análisis de discurso de orientación lingüística}

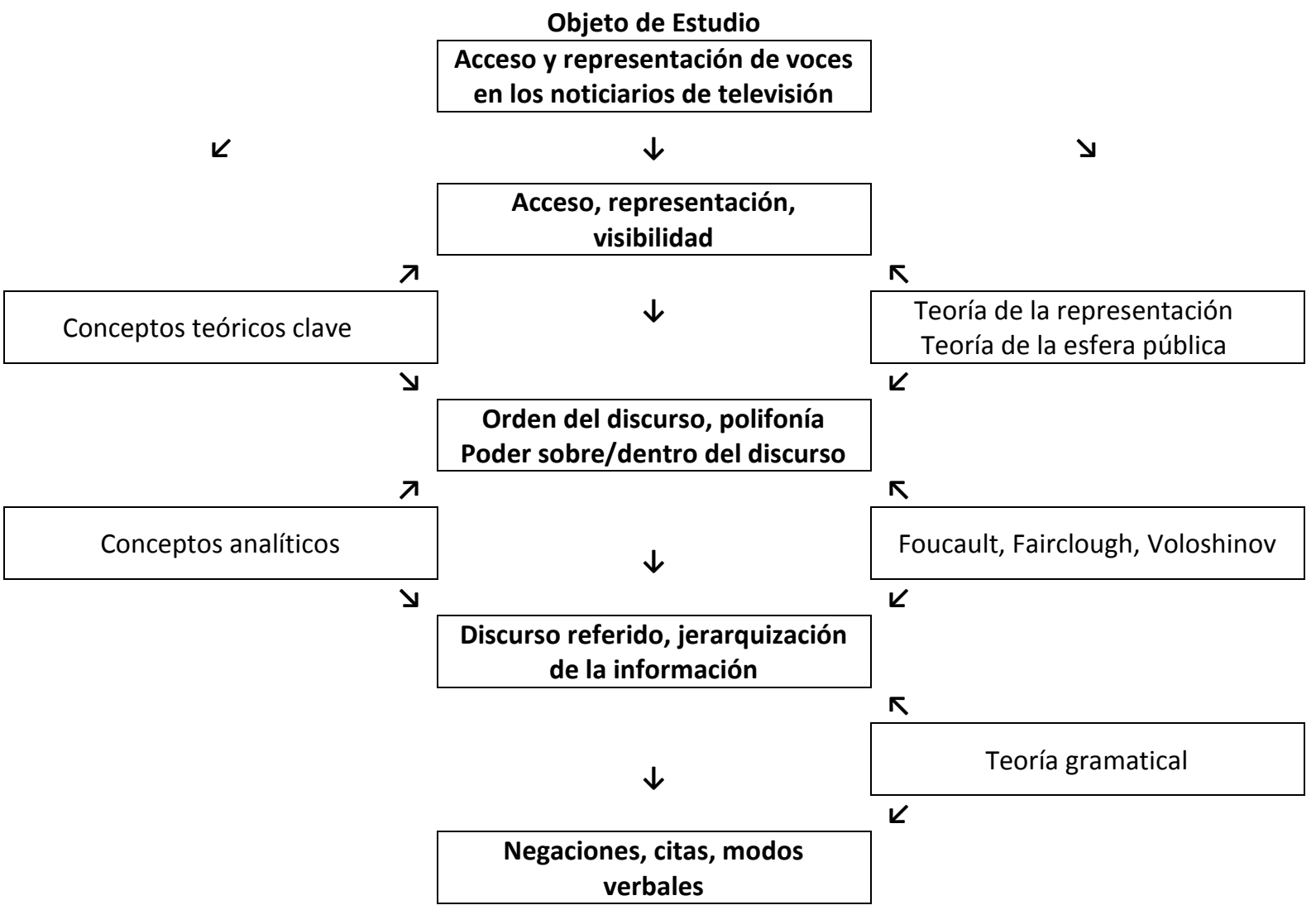

\section{Ejemplo 2}

En una segunda investigación (Santander y Aimone 2006) nuestro objeto de estudio fue la sede presidencial chilena, el Palacio de La Moneda. Como vemos, un objeto para nada lingüístico, pero que volvimos legible en el análisis. Acá nos interesaba interpretar y explicar una serie de intervenciones que durante el Gobierno de Ricardo Lagos (2000-2006) se hicieron a ese edificio (se pintó de blanco, se abrió al paso peatonal, se incorporaron mujeres a la Guardia Presidencial, etc.). Postulábamos, a modo de hipótesis, que estábamos ante una semiosis de sanación respecto del trauma que significó el ataque a ese edificio el día del golpe de 
estado (11 de septiembre de 1973). Como vemos, la noción de trauma es una primera categoría conceptual, para trabajarla la definimos de acuerdo a como lo hace el psicoanálisis (como una herida en la memoria). Nuestro propósito analítico era volver legible el Palacio de La Moneda. No trabajamos con un signo lingüístico, sino con una materia significante de otra naturaleza. Para ello y siguiendo a Verón (1984), y de acuerdo a nuestra hipótesis, conceptualizamos las intervenciones que el gobierno había realizado como operaciones discursivas de investidura de sentido, es decir, cada intervención es una operación sobre el signo La Moneda que tiene y lo dota de un sentido específico. Finalmente, para analizar y comprender dicho sentido, usamos las categorías analíticas pierceanas de índice, ícono y símbolo.

\section{Gráfico 3: Análisis de discurso de orientación semiótica}

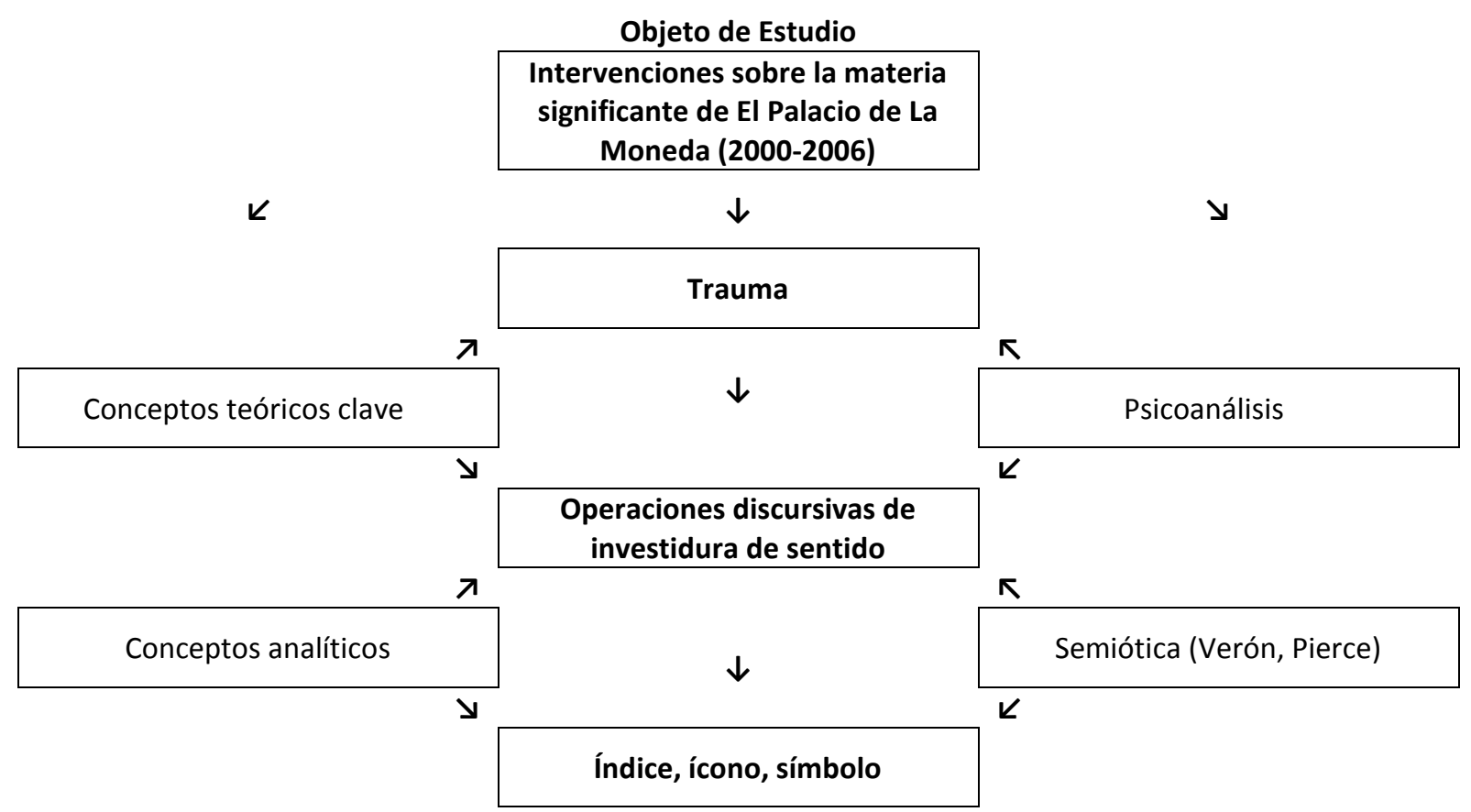

En otras oportunidades el análisis puede seguir una lógica un tanto distinta, mucho más de abajo hacia arriba. Es, por ejemplo, lo que ocurrió cuando analizamos la expresión “conflicto mapuche". En ese caso, el reiterado uso del sintagma nominal por parte de los medios chilenos llamó nuestra atención, y desde ahí, es decir, desde el sintagma mismo fuimos teorizando hacia arriba, hasta llegar a una de las funciones ideológicas del discurso, cual es, ocultar contradicciones y distorsionar la realidad.

\section{Conclusión}

La pretensión de este artículo ha sido explicar por qué y cómo hacer análisis del discurso. El desarrollo del texto siguió ese propósito, bajo la convicción de que -junto al interés y la experiencia - la teoría es el mejor apoyo para el análisis y para no perderse en los textos. En ese sentido, uno de los objetivos de este artículo fue argumentar a favor de la teoría, en tanto nos asiste el convencimiento que es antes que nada la teoría y no la técnica- la que nos permite observar científicamente los discursos. En esa línea, el analista del 
discurso se enfrenta al desafío de nutrirse conceptualmente de acuerdo al problema de investigación que aborda cada vez.

La técnica de análisis, en tanto, cumple un papel importante, pero complementario. Ello tiene que ver, sobre todo, con lo siguiente: no existe un único modelo de análisis que se pueda aplicar cada vez, por el contrario, siempre el análisis del discurso varía según los intereses que motiven la investigación, según las hipótesis que se formulen o los objetivos que se planteen. Esto provoca cierta inseguridad a veces, pero, a su vez, permite la creatividad analítica, una creatividad que gracias a la teoría y al análisis, se mantienen en los márgenes de las exigencias científicas.

No obstante y por lo mismo, este artículo propone en el último capítulo una suerte de molde analítico que se puede seguir en términos generales y en el cual la teoría guía la bajada a lo empírico. Así, mientras mayor conocimiento tengamos de propuestas y modelos de análisis, de recursos y herramientas analíticas, de categorías de análisis que han emergido en otras investigaciones, mayor será nuestra creatividad y nuestra rigurosidad heurística. Por lo mismo, el necesario conocimiento de la teoría social y discursiva que se postula, requiere ser complementado con propuestas de la lingüística y de la semiótica, para así interpretar y explicar la semiosis social.

De este modo, el afán epistémico clave, a saber, entender la dinámica texto - contexto, relacionar lo discursivo con lo social, y comprender cómo los eventos comunicativos se relacionan dialécticamente con las estructuras sociales, quedará mejor explorado.

\section{Notas}

(1) Este artículo es parte del proyecto Fondecyt 1090032.

(2) Cabe señalar que esto fue dicho a principios del siglo 20 por Voloshinov, en un momento en que aún no se observaba que los signos mismos podrían ser objetos de consumos, "bienes simbólicos", como los califica Thompson (1998), diferenciándolos así de las "formas simbólicas".

(3) Eliseo Verón (1998), por ejemplo, emplea a menudo la noción de hipótesis semiótica.

(4) Para cuidar la coherencia entre la teoría social, la teoría discursiva y la teoría gramatical, hablamos de la vigilancia epistémica; para la coherencia entre categorías conceptuales, discursivas, analíticas (lingüísticas o semióticas) y las gramaticales, hablamos de la vigilancia analítica.

\section{Bibliografía}

Aimone, E. 2007. Los Pincheira: Una parábola de la transición chilena. Cuadernos de Información 21: 21-33.

Antaki, Ch., et. al. 2003. El análisis del discurso implica analizar: Seis atajos analíticos. Atenea Digital 3: 1-22. http://psicologiasocial.uab.es/athenea/index.php/atheneaDigital/index

Austin, J. 1982. Cómo hacer cosas con palabras. Barcelona: Paidós

Barthes, R. 1971. Elementos de semiología. Madrid: Alberto Corazón Editor.

Bourdieu, P. 2003. Doxa y vida cotidiana. En: Zizek, S. (ed). Ideología. México: FCE, pp. 295-308. 
Bourdieu, P. 2000. El oficio del sociólogo. Buenos Aires: Siglo XXI Editores.

Echeverría, R. 2003. Ontología del lenguaje. Santiago: J.C. Sáez Editor.

Fairclough, N. 2003. El ACD como método para la investigación en ciencias sociales. En: Wodak, R. y Meyer, M. (eds.). Métodos de análisis crítico del discurso. Barcelona: Gedisa, pp.143-178.

Fairclough, N. 1995. Critical discourse analysis. London: Longman.

Fairclough, N. 1992. Discourse and social change. Cambridge: Polity Press.

Fairclough. N. 1989. Language and power. London: Longman

Foucault, M. 1983. El orden del discurso. España: Tusquets.

Fowler, R. 1996. Language in the news. Discourse and ideology in the press. London: Routledge.

Fowler, R. et. al. 1983. Lenguaje y control. México: FCE.

Fraser, N. 2003. Nuevas reflexiones sobre el reconocimiento. New Left Review 4: 107-120.

Garretón, M.A. 2007. Del postpinochetismo a la sociedad democrática. Santiago: Prometeo.

Grice, H.P. 1991. Lógica y conversación. En: Valdés, L. (ed.). La búsqueda del significado. Madrid: Tecnos, pp. 551-530.

Kress, G. y Van Leeuwen, T. 1998. Front pages: (The critical) analysis of newspaper layout. En: Bell, A. y Garret, P. (Eds.) Approaches to media discourse. London: Blackwell, pp. 186-219.

Halliday, M.A.K. 1994. El lenguaje como semiótica social. Bogotá: FCE.

Halliday, M.A.K. y Hasan, H. 1990. Language, context, and text: Aspects of language in a socio-semiotic perspective. Oxford: Oxford University Press.

Hodge, R. y Kress, G. 1979. El lenguaje como ideología. Buenos Aires: Universidad de Buenos Aires.

Horkheimer, M. y Adorno, T. 1969. Dialéctica del iluminismo. Madrid: Trotta.

Hurtado, J. 2004. Cómo formular objetivos de investigación. Bogotá: Cooperativa Editorial Magisterio.

Canales, M. 2006. Metodologías de la investigación social. Santiago: LOM.

Ibáñez, T. 2003. El giro lingüístico. En: Análisis del Discurso. Manual para las ciencias sociales. Barcelona: Editorial UOC, pp. 21-42.

Laclau, E. y Mouffe, Ch. 2004. Hegemonía y estrategia socialista. México: FCE.

Larraín, J. 2007. El concepto de ideología. Santiago: LOM.

Marx, C. 2008. Introducción a la crítica de la economía política 1857. Buenos Aires: Ediciones Luxenburg. 
Pardo, M.L. 1996. Derecho y lingüística: Cómo se juzga con palabras. Buenos Aires: Ediciones Nueva Visión.

Pardo, M.L. 1986. Hacia una redefinición de las nociones de tema y rema. De la oración al discurso. Cuadernos del Instituto de Lingüística 1(1): 59-93.

Reich, W. 1993. La función del orgasmo. Barcelona: Paidós.

Santander, P. 2007. ACD y análisis de los medios. En: Santander, P. (ed). Discurso y crítica social. Santiago: E.O.C, pp. 27-43.

Santander, P. y Aimone, E. 2006. The palace of La Moneda: From the trauma of the hawker hunters to the therapy of the signs. Semiotica 158: 365- 382.

Saussure. F. 1997. Curso de lingüística general. Buenos Aires: Losada.

Sayago, S. 2007. La metodología de los estudios críticos del discurso. En: Santander, P. (ed). Discurso y crítica social. Santiago: E.O.C, pp. 45-59.

Sperber, D. y Wilson, D. 1994. La relevancia. Madrid: Visor.

Tannen, D. 1996. Género y discurso. Barcelona: Paidós.

Thompson, J. 1998. Los media y la modernidad. Barcelona: Paidós Comunicación.

Valles, M. 2000. Técnicas cualitativas de investigación social. Madrid: Síntesis.

Van Dijk, T. 2000. El discurso como interacción social. Barcelona: Gedisa.

Verón, E. 1984. Semiosis de lo ideológico y del poder. Buenos Aires: Universidad de Buenos Aires.

Verón, E. 1998. Semiosis social. Buenos Aires: Gedisa.

Voloshinov, N. 1992. Marxismo y filosofía del lenguaje. Madrid: Alianza Universidad.

Williamson, R. 2002. Situación comunicativa y estructura genérica en la telenovela mexicana. Revista Latinoamericana de Estudios del Discurso 2(1): 51-68.

Zizek, S. 2003. Ideología. Buenos Aires: FCE.

Recibido el 23 Dic 2010

Aceptado el 15 Mar 2011 